Article

\title{
A Framework to Tackling the Synchrony between Social and Ecological Phases of the Annual Cyclic Movement of Transhumant Pastoralism
}

\author{
Natalia Pérez León, Octavio Bruzzone and Marcos H. Easdale * \\ Instituto de Investigaciones Forestales y Agropecuarias Bariloche (IFAB), INTA-CONICET, \\ San Carlos de Bariloche 8400, Argentina; perezleon.natalia@inta.gob.ar (N.P.L.); \\ bruzzone.octavio@inta.gob.ar (O.B.) \\ * Correspondence: easdale.marcos@inta.gob.ar; Tel.: +54-294-442-2731
}

Received: 25 March 2020; Accepted: 21 April 2020; Published: 24 April 2020

\begin{abstract}
Transhumant pastoralism is mobile livelihood strategy in which families and their herds move seasonally from lowlands, where they settle during the winter, towards the highlands, located in mountainous areas, during the summer. We propose a framework, rooted in a socio-environmental coevolutionary perspective, for the transhumant annual cycle as comprised by the winter-phase, the summer-phase, and movement transitions between them. The aim was to assess the level of synchrony between ecological phases and social phases and the benefit of moving between pasturelands in selected study cases from Patagonia, Argentina. Ecological phases were addressed by the difference between vegetation productivity of winter- and summer-lands, with Fourier transform applied to data series of the Normalized Difference Vegetation Index (NDVI). Social phases were estimated by the proportion of annual time spent by pastoralists and their herds in each site and during transitions, respectively, obtained from interviews. The framework was sensitive to capturing differences across study cases. There was an observed tendency towards more synchronisation in the cases with closer distances and asynchrony in the cases with longer distances and longer movement transitions between pasturelands. Results are encouraging as a step towards the development of a monitoring system of both transhumant pastoralism activity and environmental changes.
\end{abstract}

Keywords: climate change; coevolution; Fourier transform; grazing; mobile systems; NDVI; Patagonia; social-ecological systems

\section{Introduction}

The integration of social and ecology sciences is emphatically required to attain sustainable development in arid and semiarid regions [1]. Nevertheless, whereas theoretical proposals in the field of socio-ecological system research have been increasingly developed over the last two decades, methodologies and many operative issues are still major barriers to facilitating a more integrated understanding [2-4]. Socio-ecological systems are complex, adaptive and co-evolving, delimited by spatial or functional boundaries surrounding specific ecosystems and their problem context [5]. Mobile pastoralism is a kind of complex socio-ecological system, the configuration and functional patterns of which are the result of a historical socio-environmental coevolution [6,7].

A coevolutionary approach was proposed as a theoretical basis to understand the interdependence of social and environmental dynamics and explain changes in a given region, human activity or local community [8,9]. However, a main concern of socio-ecological coevolution research is also related to the obstacles in shortening the gap between theory and application. Few research programs 
have explored questions through a coevolutionary framework and gained new insights, because empirical applications are still lacking [10]. To overcome these difficulties, the same scholars insist that socio-environmental coevolutionary frameworks require identifying critical categories, bounding processes and defining analytical boundaries, by taking a pragmatic approach of engagement with empirical phenomena. Tackling the synchrony between the social and ecological phases of the annual cyclic transhumant movement is rooted in a widely documented empirical phenomenon about this kind of mobile systems. We propose that these phenomena are a result of a socio-environmental coevolutionary process.

Mobility in human societies is an ancient livelihood strategy of adaptation to spatial and temporal environmental variability [11]. Transhumant pastoralism is a kind of mobile strategy in which people and their herds move seasonally from lowlands (e.g., valleys and arid and semi-arid plains), which are pastured during winter, towards the highlands, located in mountainous areas, during summer. This kind of transhumant pastoralism is the most frequent worldwide, known as vertical movement. However, seasonal movements of pastoralists and their herds, following the same annual cyclic pattern and visiting the same pasture sites, can occur between pasturelands with different vegetation compositions and provision of water, which are also spatially fragmented but are located at similar heights. This kind of transhumant pastoralism is less frequent, known as horizontal movement. In order to include both kinds of transhumant activity, hereafter the references to pasturelands will be based on the season in which the sites are pastured: winter-land and summer-land, respectively.

The seasonal movement is performed using communal herding roads, which interconnect these different pasturelands. Hence, a transhumant pastoral system is comprised by three key subsystems: (i) winter-land, (ii) summer-land and (iii) herding roads [12]. With this annual cyclic movement, pastoralists take advantage of the regional heterogeneous forage productivity and quality of rangelands [13]. This strategy implies that pastoralists and their herds escape from seasonal water scarcity and lower forage productivity occurring in the lowlands during summer, as well as from snowfall and harsh conditions in the mountains during winter. Hence, pastoralists seize opportunities from this heterogeneity in order to maximise their overall benefit [6].

These upward and downward movements represent different phases of an annual cycle of transhumant pastoral lifestyle. From a biophysical perspective, phases can be defined by differences in rangeland productivity dynamics. Forage productivity occurs in early spring in the lowlands, whereas, in the highlands, it is concentrated in the summer. Water is much more available in winter and spring, while it significantly decreases during the summer in lowlands. On the other hand, water is abundant after the spring and throughout the summer due to snow melting, whereas access is interrupted in winter due to snow and harsh climate in the highlands. Primary productivity is a variable that synthesises ecosystem structure and functioning [14]. Forage production is a fraction of the Aboveground Net Primary Production (ANPP), which is frequently estimated with spectral indexes obtained from satellite remote sensing data such as the Normalised Difference Vegetation Index (NDVI) [15]. Hence, NDVI is a proxy for the energy absorbed by vegetation [16]. We propose that differences in the NDVI temporal dynamics of winter- and summer-lands characterise the different ecological phases associated with the benefit of moving for transhumant pastoralism. This benefit refers to the access to forage and water for herds in different places, which promotes the social phases of the transhumant system.

From a social perspective, phases can be defined by the time spent by pastoralists and their herds in each pastureland, where they transitorily develop their life. Lowlands are warmer in the winter and, in general, closer to urban areas, where children attend school and families stock up on food and get health assistance [17]. Pastoral households have their main house in the lowlands where they spend most of the year. Highlands are more temperate in the summer due to higher height, but remote from urban areas, lacking social services and infrastructure such as roads and electricity. In general, pastoral families live in very precarious huts or shelters. However, since most pastoral households move to the mountains, summer-lands are nodes of regional pastoral networks that promote high connectivity 
due to the arrival of people from very different places [18]. Hence, highlands in the summer constitute a core of social meetings, where festivals and different social events occur, and the exchange of animals and handicraft takes place.

This mobile strategy of different human societies is well documented worldwide. Many studies explored a range of features, such as archaeological evidences [19,20], socioeconomic characterisations [21-23], traditional ecological knowledge of these pastoral communities [24-28], biophysical variability, pastoral rights and access to resources [29,30], migratory routes, landscape connectivity and transhumant networks [18,31-34], challenges and future scenarios of global or regional change [12,35-39]. With respect to methodologies aimed at estimating spatial and temporal dimensions of pastoral mobility, recent studies have focused on tracking migratory roads [31], characterising movements and connectivity networks between fragmented pasturelands [18,32], and simulating movements according to varying fodder supply [33]. To the best of our knowledge, an approach to tackling and estimating the benefit of moving, based on the level of synchrony of social and ecological phases of the annual cycle movement is still lacking. We argue that the relative synchrony of these phases depicts a key functional feature of the socio-ecological interdependence in transhumant systems. In this respect, the proposed methodological approach is innovative in providing new insights to tackling the relative benefit of the annual cyclic movement and measures for its quantification.

The aim was to assess the level of synchrony between ecological and social phases of transhumant pastoralism and the benefit of moving between pasturelands from the perspective of forage supply for livestock. Our research was guided by the following questions: (i) what is the annual gross benefit of the cyclic movement from winter-lands to summer-lands and vice versa, in terms of the supply of forage productivity?, (ii) what is the relative contribution of winter-lands and summer-lands to this annual benefit?, and (iii) which is the level of synchrony between the time spent by transhumant pastoralists in each pastureland and its ecological phases, respectively? Ecological phases refer to a functional dimension of ecosystems, based on a comparison of temporal dynamics of rangeland productivity, and were measured by the difference between NDVI-integral of winter- and summer-lands, with Fourier transform. This framework was tested in four case studies from North-West Patagonia, Argentina. Likewise, social phases refer to living alternatively in two different places depending on the season and were estimated by the proportion of annual time spent by pastoralists in each pastureland, respectively. This information was obtained from interviews with pastoralists of the same case studies, respectively. We discuss the contribution of the proposed framework in providing new insights for current debates on landscape use and the sustainability of mobile socio-ecological systems. Besides, we identify key future steps aimed at pursuing the development of a monitoring system of changes in the synchrony of social and ecological phases, as a tool to providing early warnings and measuring impacts on both transhumant pastoralism and the interdependent ecosystems.

\section{Materials and Methods}

\subsection{Conceptual Framework of the Transhumant Annual Cycle}

We propose a framework of the transhumant annual cycle, which is broadly defined by two phases: (i) winter-phase and (ii) summer-phase (Figure 1). From an ecological domain perspective, the main premise is that the seasonal differences in vegetation productivity between winter- and summer-lands define the gross benefit of moving from one pastureland to the other. During the winter-phase, the primary productivity of winter-lands is higher than the productivity of summer-lands. This is due to a strong reduction in vegetation activity because of snow cover and cold conditions in the mountains. Hence, the integral of the difference of vegetation productivity levels between them defines the benefit of the winter-phase. On the other hand, during the summer-phase, primary productivity in summer-lands is higher than the productivity of winter-lands, as promoted by available water from snow melting and higher temperatures in the spring and summer seasons in the mountains. The integral of the difference in vegetation productivity between them defines the benefit of the summer-phase. 
Then, the points identifying intersects between both winter- and summer-land productivity curves $(\mathrm{Fd}, \mathrm{Fu}$, Figure 1) define the starting and finishing time thresholds, which determine the periods of both phases, respectively. The relative benefit of each pastureland is also measured by the proportion of the time of the year in which this benefit is supplied and it is compared with the time spent by transhumant pastoralists in each site, respectively.

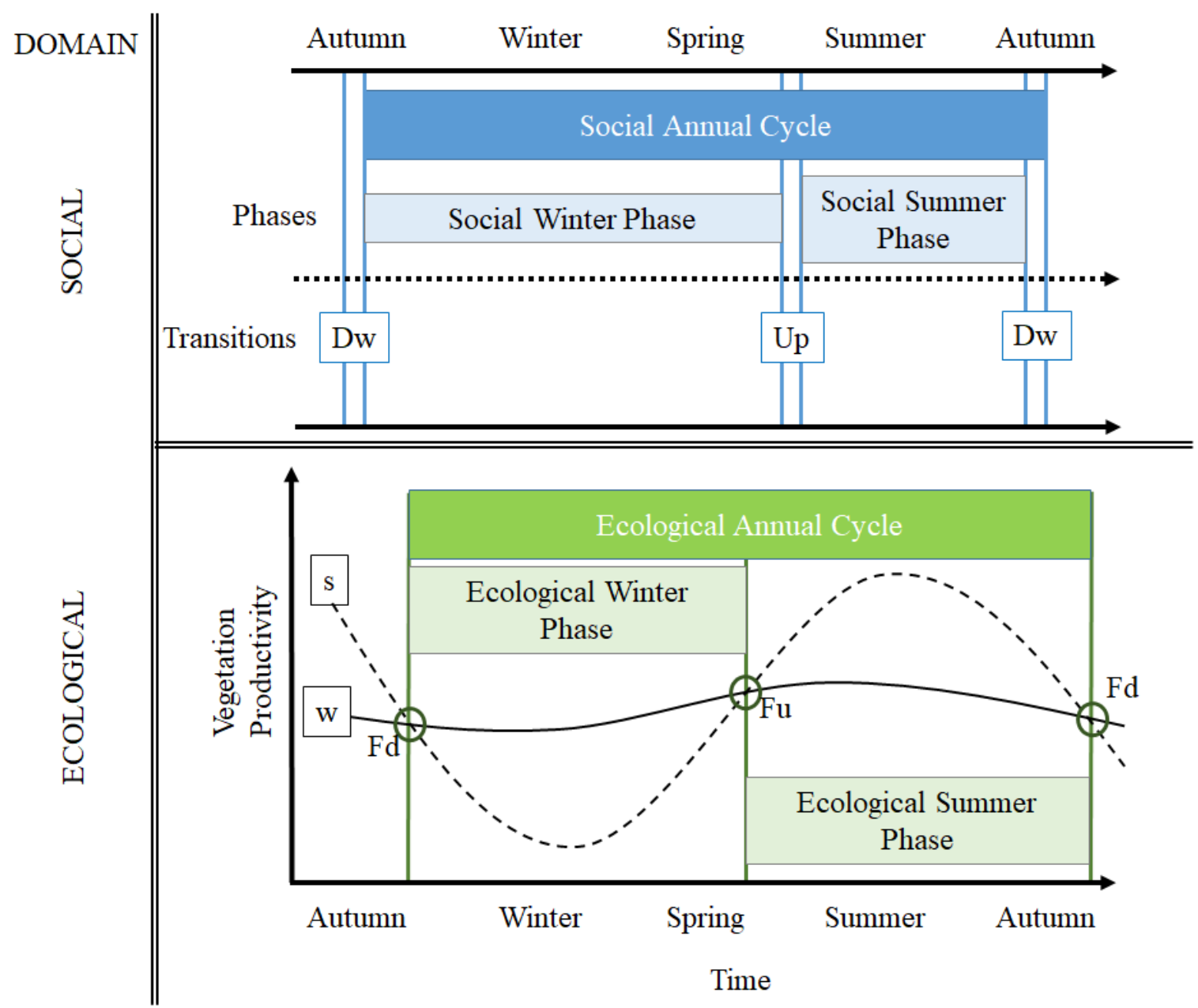

Figure 1. Conceptual framework of the transhumant annual cycle, as defined by the lowland-phase and the highland-phase along time, for the social and ecological system domain, respectively. In the social domain, straight blue lines identify starting and ending dates of transitions between phases. References: Downward (Dw) and Upward (Up) transitions. In the ecological domain: straight green lines identify starting and ending dates of phases, based on the intersect points between both winter- and summer-land productivity curves (Fd, Fu). References: winter-land vegetation dynamics ( $w$, full black line) and summer-land vegetation dynamics (s, cut black line).

From a social domain perspective, the yearly Social Annual Cycle (SAC) is defined by the moment in which pastoralists arrive at their respective winter-land (i.e., end of downward transition). Then, the Social Winter Phase (SWP) is defined by the arrival date to winter-lands until the starting of upward moving transition, whereas the Social Summer Phase (SSP) is defined by the arrival date at summer-land (end of upward moving transition) and the start of the downward transition (Figure 1). The movement of herds and pastoralists from winter-land to summer-land defines the transition between the winter-phase towards the summer-phase, which is named upward transition movement (Up). The movement of herds and pastoralists from summer-land to the winter-land defines the transition between the summer-phase towards the winter-phase, which is named downward transition movement $(\mathrm{Dw})$. The duration of these transitions varies among cases, depending mainly 
on the distance between pasturelands (e.g., shorter distances need one or few days, whereas longer distances need almost 30 days). Hence, the effective summer-phase is a fraction from the total summer-phase, depending on the time spent for transitions. The overall benefit of the transhumant annual cycle is determined by the sum of the respective benefits from the winter and summer phases.

\subsection{Study Cases}

We selected four study cases from north-west Patagonia, Argentina, with different biophysical features involved in each transhumant pastoralist (Figure 2). Based on previous research and extension activities with pastoralists in the study area $[27,40]$, we considered the following criteria to select the cases: (i) different geomorphological regions and hydrological basins, (ii) location and height of winter- and summer-lands, including both horizontal and vertical transhumance (iii) physical distance between winter- and summer-lands (Table 1). Cases 1 and 2 represent horizontal transhumance, for which height differences are small and lengths between pasturelands are short. For case 1, the dominant vegetation of winter-land is shrub-grass steppes, similar to the summer-land, including also a small area of meadow ( $28 \%$ of area). Case 2 has more contrasting vegetation, for which medium height shrub steppes dominate in the winter-land, whereas a meadow (60\% of area) and shrub-grass steppes dominate in the summer-land [41]. Cases 3 and 4 represent vertical transhumance, for which height differences are large and lengths between pasturelands are long (Table 1). For both cases, medium height shrub steppes dominate in the winter-lands and grass-shrub steppes in the summer-lands, with a small area of meadow in case 4 .

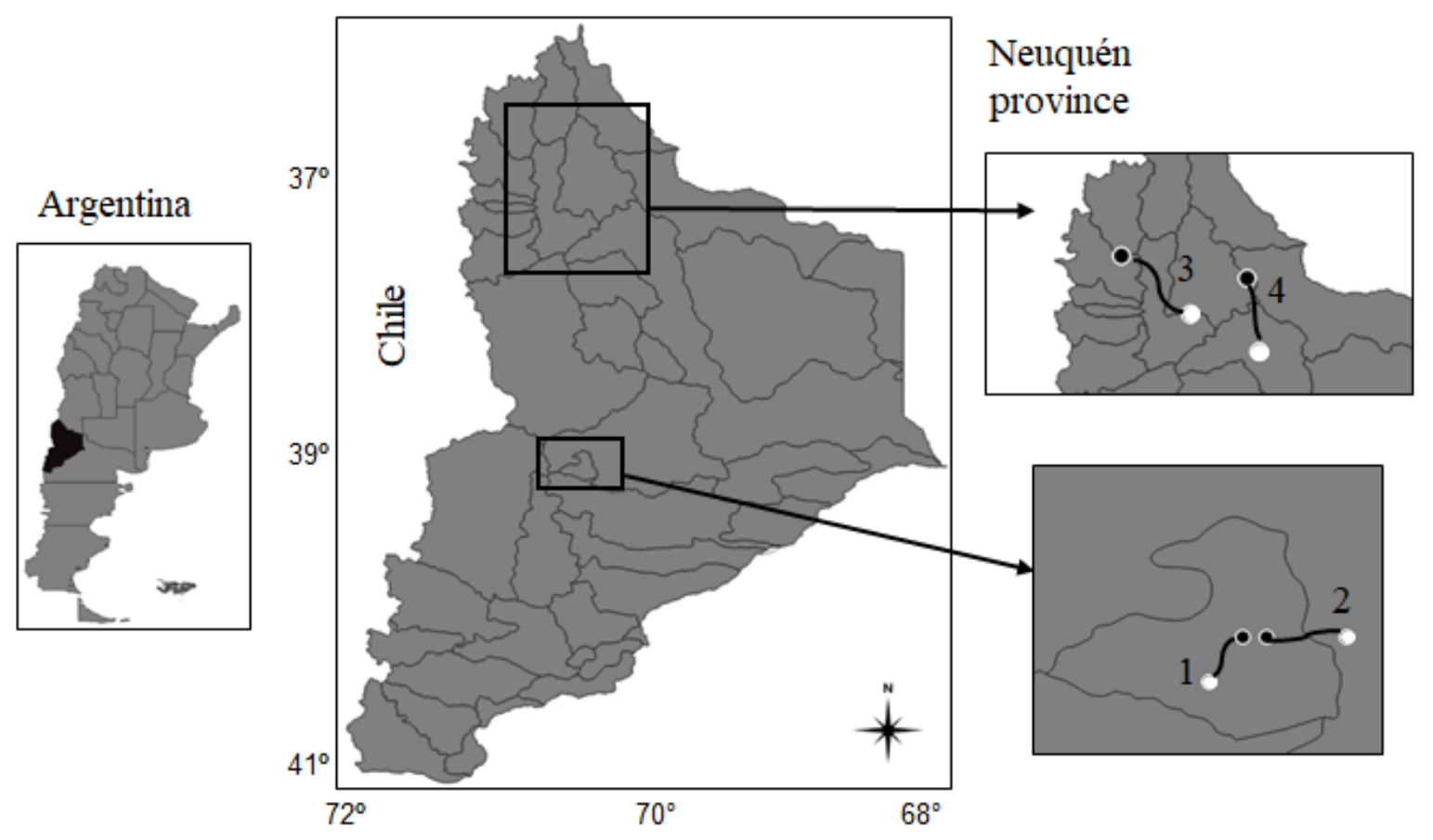

Figure 2. Study areas from north-west Patagonia, in Neuquén province, Argentina. Winter-lands (white nodes), summer-lands (black nodes) and herding roads (black lines linking nodes) are identified for the study cases, respectively. References: River basins in Neuquén province (grey lines). 
Table 1. Area (ha) and average height (meters above sea level) of winter-lands and summer-lands, height difference (meters, summer-land with respect to winter-land) and length $(\mathrm{km})$ of herding roads between pasturelands, for the study cases, respectively.

\begin{tabular}{|c|c|c|c|c|c|c|c|c|}
\hline \multirow{3}{*}{ Herder } & \multicolumn{6}{|c|}{ Pasturelands } & \multirow{2}{*}{\multicolumn{2}{|c|}{ Herding Road }} \\
\hline & \multicolumn{3}{|c|}{ Winter-Land } & \multicolumn{3}{|c|}{ Summer-Land } & & \\
\hline & Area (ha) & Height (m) & $\begin{array}{l}\text { Dominant } \\
\text { Vegetation }\end{array}$ & Area (ha) & Height (m) & $\begin{array}{l}\text { Dominant } \\
\text { Vegetation }\end{array}$ & $\begin{array}{c}\text { Height } \\
\text { Difference (m) }\end{array}$ & Length (km) \\
\hline Case 1 & 469 & 1281 & Shrub-grass steppe & 1812 & 1287 & $\begin{array}{l}\text { Shrub-grass steppe, } \\
\text { small meadow }\end{array}$ & 6 & 6 \\
\hline Case 2 & 1475 & 1284 & Shrub steppe & 1169 & 1275 & $\begin{array}{c}\text { Meadow, } \\
\text { Shrub-grass steppe }\end{array}$ & -9 & 4 \\
\hline Case 3 & 1337 & 1040 & Shrub steppe & 1994 & 1483 & Grass-shrub steppe & 443 & 72 \\
\hline Case 4 & 1237 & 1020 & Shrub steppe & 700 & 1420 & $\begin{array}{l}\text { Grass-shrub steppe, } \\
\text { small meadow }\end{array}$ & 400 & 85 \\
\hline
\end{tabular}

\subsection{Social Data}

The social phases were estimated by the real time spent by each pastoralist for living in the winterand summer-land, respectively, and the time spent for movement transitions between them. This information was based on pastoralists' knowledge about the dates, used as references to define the start of upward and downward movements, respectively, and hence to organize their living. We also inquired about the time spent for each movement transition. This information was obtained from interviews with each pastoral family in the years 2014 and 2015. Phases and transitions are presented as proportions of yearly time. Additionally, the respective grazing areas for each pastoralist were obtained from previous research conducted in their farming systems and confirmed during interviews [40], which were used for the ecological analysis.

\subsection{Ecological Data}

\subsubsection{Data Source and Analysis}

We used the 16-day composite MODIS images (MODIS13Q1 product) for the series February 2000-February 2019, which were obtained from the United States Geological Survey (USGS), Earth Resources Observation and Science (EROS) Data Center. The pixels from the selected study areas (i.e., $250 \times 250 \mathrm{~m}$ of spatial resolution) were clipped by means of a point-inside-polygon routine from the Matplotlib library of Python programming language [42]. This procedure automatically detects if any of the four corners of the pixel is found inside the polygon of the study area, or which of the corners of the study area are found inside a given pixel. For these cases, the pixel is then considered inside the study area. The sequence of clipped MODIS images was piled up into a space-time cube (i.e., a three-dimensional matrix comprised by longitude, latitude, and time). Hence, we obtained the temporal sequence for each pixel along the last dimension of that matrix (i.e., time).

NDVI was used as a proxy of vegetation primary production [15,43], and was derived from MODIS images, calculated with the following equation

$$
\mathrm{NDVI}=(\mathrm{NIR}-\mathrm{R}) /(\mathrm{NIR}+\mathrm{R})
$$

where R and NIR are the surface reflectances centered at 648 (visible) and $858 \mathrm{~nm}$ (near-infrared) portions of the electromagnetic spectrum, respectively.

\subsubsection{Data Processing}

A multiple band-pass filtering was applied to the NDVI time series in order to obtain the mean annual cycle, by removing all the other frequency components using the Fast Fourier Transform (FFT). After performing the FFT, we obtained the Fourier transform of the time series. Then, we suppressed all the frequency components that were not an integer multiple of the annual frequency. After that procedure, we obtained the zero frequency (the mean), and the harmonics of the annual cycle. Then, 
we performed the inverse Fourier transform in order to obtain the filtered series, which only kept the mean and the annual cycle.

\subsubsection{Estimation of Gross Benefits}

We propose that Benefit of the Transhumant Annual Cycle (BTAC) can be estimated by using the NDVI dynamics as a proxy for vegetation productivity of each pastureland. BTAC is comprised by the Benefit of the Ecological Winter Phase (BEWP, as a reference of the winter-land supply), and the Benefit of the Ecological Summer Phase (BESP, as a reference of the summer-land supply).

Hence, the benefit of each place was estimated by the following equation

$$
B_{i} \propto \int_{j}^{d} V_{i}(t) d t
$$

where $B$ is the benefit of the ecological phase of site $i$ defined as the integral of the spectral vegetation index $V$, which is measured between January $(j)$ and December $(d)$.

The gross benefit of moving from place $w$ (winter-land) to $s$ (summer-land), named Benefit of the Ecological Summer Phase (BESP), and vice versa, named Benefit of the Ecological Winter Phase (BEWP), was estimated by the difference in seasonal productivity between them (Vi). Hence, in the summer-phase $V i=(V s-V w)(V s>V w)$ and in the winter-phase $V i=(V w-V s)(V w>V s)$, where $V w$ is the integral of the spectral index for the winter-land and $V s$ for the summer-land. In particular, the integral of the maximum of the two functions, discounting the minimum of these two functions, were estimated as follows

$$
B \propto\left\{\begin{array}{c}
\int_{t=j}^{d}\left(\delta\left(V_{w}(t)-V_{s}(t)\right)\left(V_{w}(t)>V_{s}(t)\right)+(1-\delta)\left(V_{s}(t)-V_{w}(t)\right)\left(V_{s}(t)>V_{w}(t)\right)\right) d t V_{w}(t)=V_{s}(t) \exists(j, d) \\
0 \quad \text { otherwise }
\end{array}\right.
$$

where $B$ is the benefit of moving seasonally from $w$ to $s$, and vice versa, $V w$ identifies the integral of the spectral index for the winter-land and $V s$ for the summer-land. Finally, $\delta$ is a Kronecker delta, which is equal to one in winter, and zero in summer, so in winter only the first term of the equation is activated. On the other hand, in the summer, that term becomes zero and the second term is equal to one, becoming active. The benefit is different from zero only if the estimated productivity $V w(t)$ and $V s(t)$ intersect in the time interval $(j, d)$. Otherwise, the benefit is zero when one of the pasturelands has always a higher productivity along the year.

The ecological dates identifying the limits of each phase were estimated by calculating the crossing points of both benefit curves (Fd, Fu, Figure 1). For this, straight lines were adjusted near to the crossing points and the intersection was calculated.

The Benefit of the Ecological Summer Phase (BESP) does not consider the effective time that the pastoralists spent in the summer-land, which can be less than potential (Social Summer Phase (SSP)). Therefore, in the cases where SSP was shorter than ESP, we included an estimation of the Effective Benefit of the Ecological Summer Phase (BESPe), which was a portion of the total benefit.

\section{Results}

The overall annual benefit of the transhumant annual cycle (BTAC) was positive in most cases (Table 2), except for one in which both winter- and summer-land NDVI series had similar dynamics and there was no crossing-over between them (case study 1, Figure 3). In those cases where ecological phases could be accounted for, the relative benefit provided by the summer-phase (BESP) was similar or greater than the relative benefit provided by the winter-phase (BEWP) (Table 2; Figures 4-6). For these case studies, the ecological summer-phase (ESP) represented almost $60 \%$ of the annual period. Since the transition time used to move between pasturelands lasted between $5 \%$ and $10 \%$ of the annual period, the effective ESP represented between $50 \%$ and $55 \%$ of the year (Figures 5 and 6 ). Because of this reduction in the period of the ESP, the effective benefit (BESPe) was lower than the total benefit 
provided by the summer-phase (BESP). On the other hand, ecological winter-phase (EWP) represented $40 \%$ of the annual period. However, the annual period spent by the pastoralists and their herds to pasture on the winter-lands lasted between $65 \%$ and $70 \%$ of the year (SWP). These results suggest a comparatively longer pastured time of livestock on winter rangelands than on summer rangelands, as measured by the time spent in each site, respectively.

Table 2. Duration (days) and percentage of the Benefit of the Ecological Summer Phase (BESP), the Benefit of the Winter Phase (BEWP) and Benefit of the Transhumant Annual Cycle (BTAC) (see Equations (2) and (3)). Starting and ending dates of ecological phases, based on the intersect points between both winter- and summer-land productivity curves (Fd, Fu, see Figure 1), starting and ending dates of transitions and total time spent for upward and downward transitions, for the study cases, respectively.

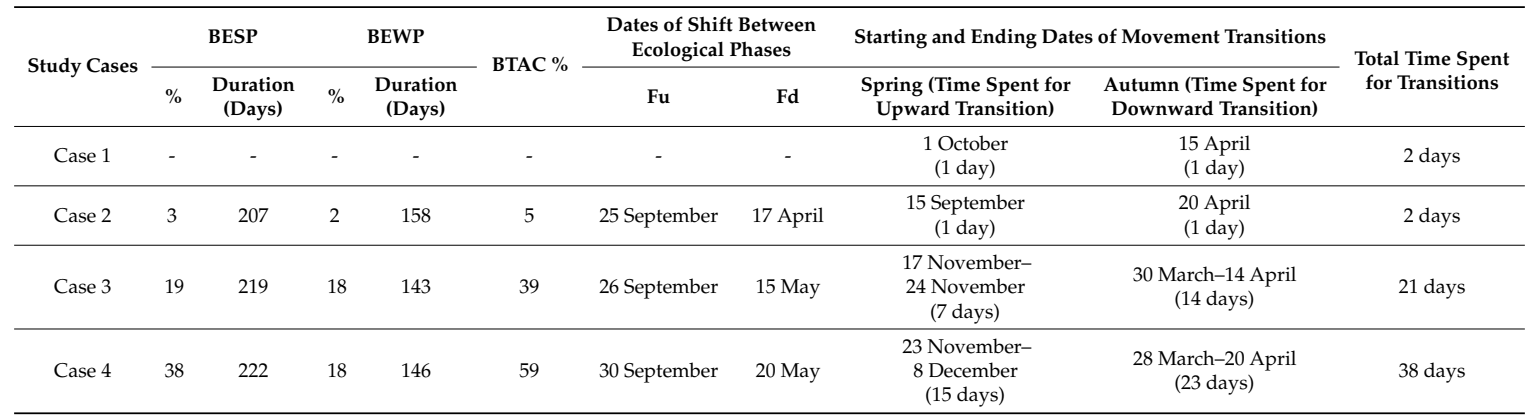

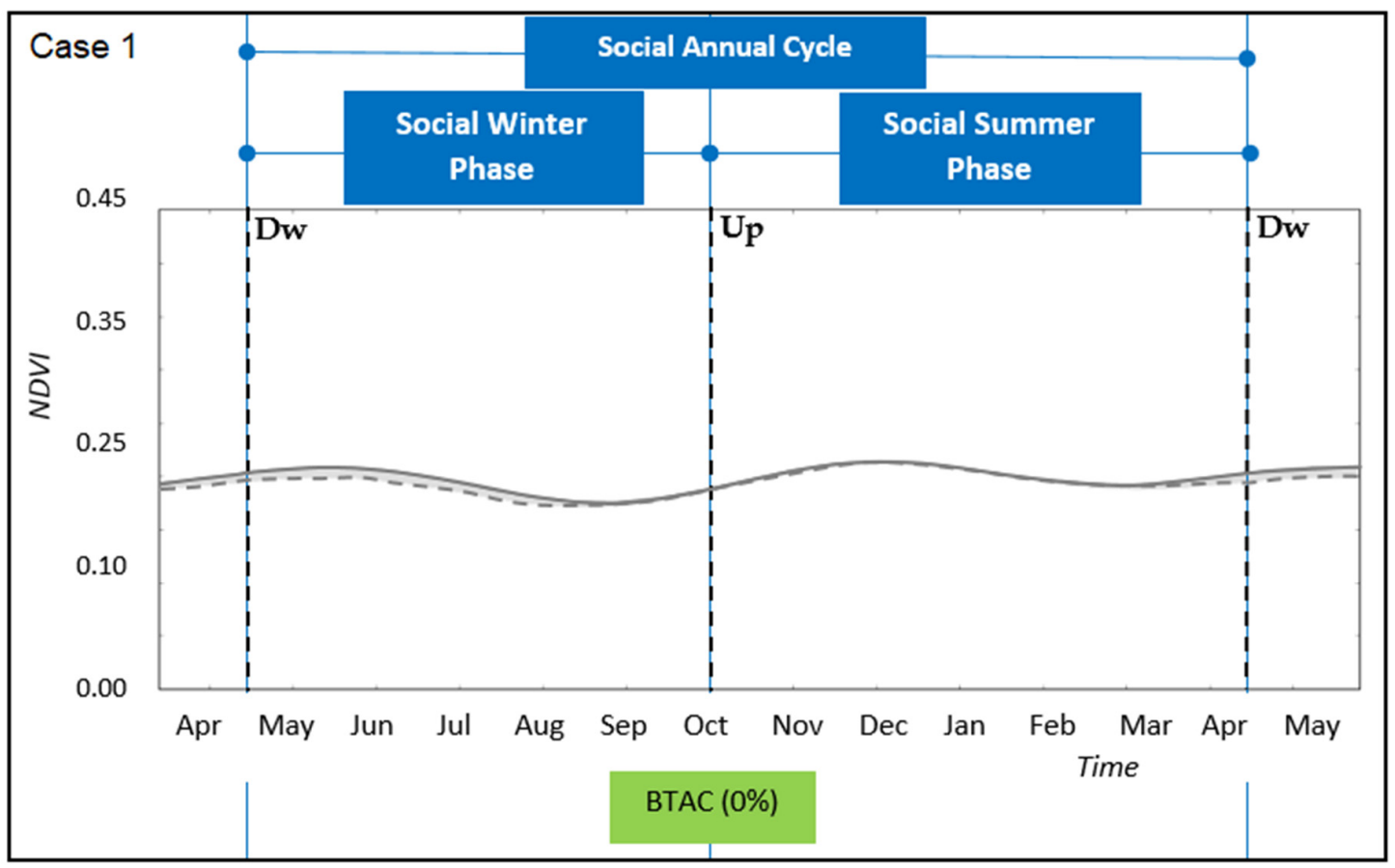

Figure 3. Transhumant annual cycle for the case study 1. Winter-phase and summer-phase along time for the social system domain (straight blue lines). Upward (Up) and Downward (Dw) transition periods are identified by cut lines, respectively. Winter-land vegetation dynamics (full grey line) and summer-land vegetation dynamics (cut grey line). 


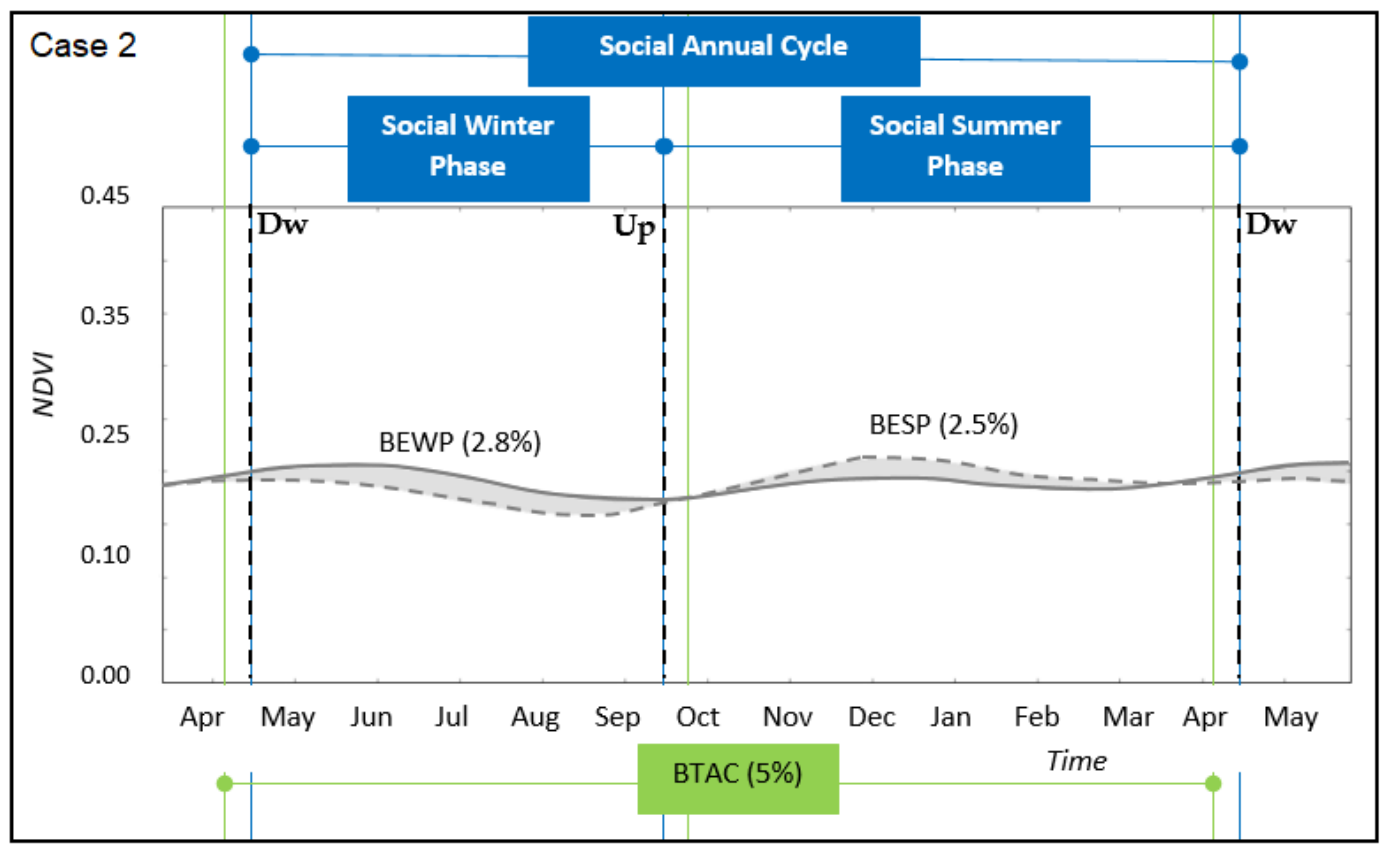

Figure 4. Transhumant annual cycle for the case study 2. Winter-phase and summer-phase along time for the social (straight blue lines) and ecological (straight green lines) system domain. Upward $(\mathrm{Up})$ and Downward (Dw) transition periods are identified by cut lines, respectively. Winter-land vegetation dynamics (full grey line) and summer-land vegetation dynamics (cut grey line). Grey areas identify the gross benefit of the ecological winter phase (BEWP) and summer phase (BESP), respectively (Equation (2)). References: Benefit of Transhumant Annual Cycle (BTAC, Equation (3)).

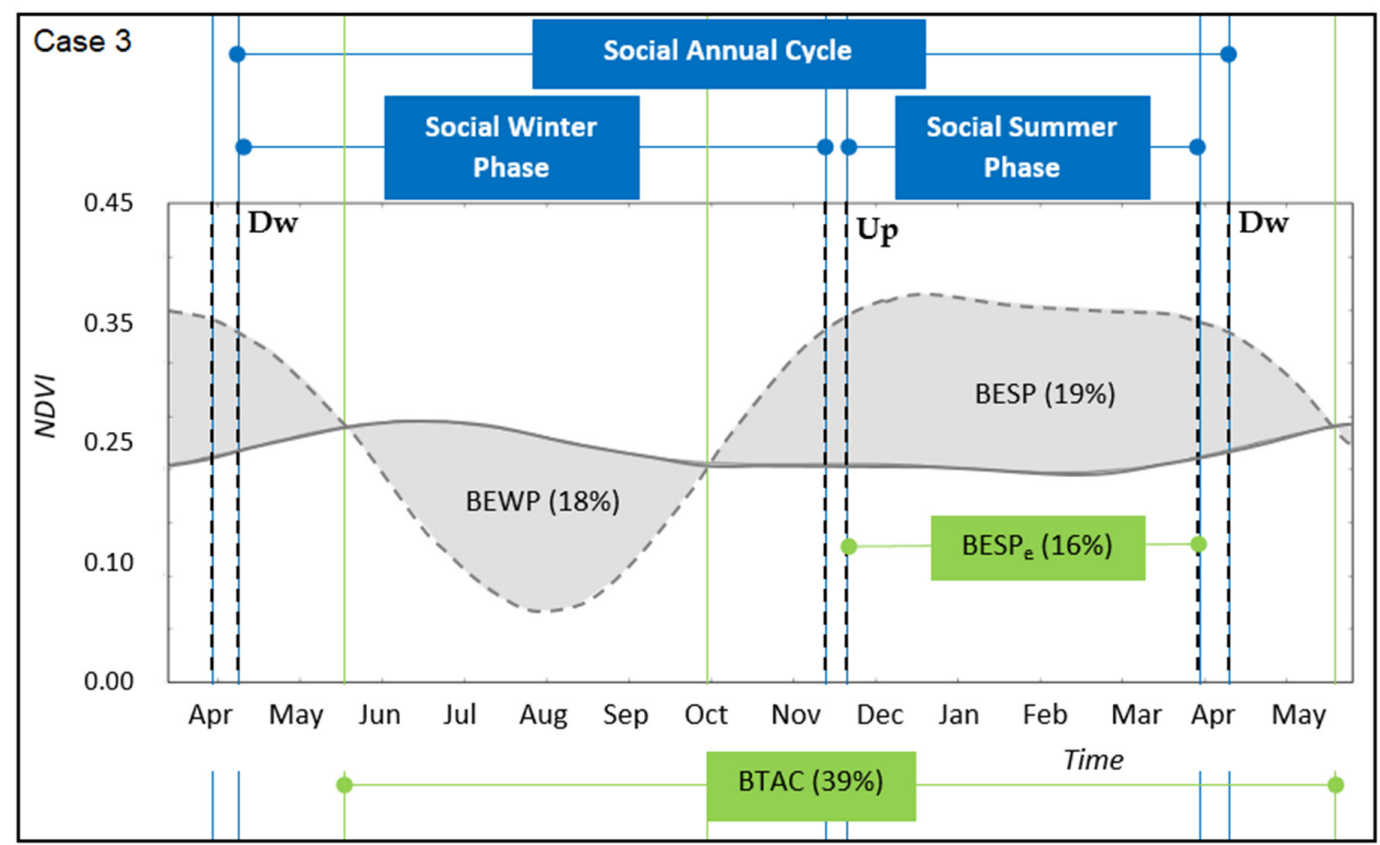

Figure 5. Transhumant annual cycle for the case study 3. Winter-phase and summer-phase along time for the social (straight blue lines) and ecological (straight green lines) system domain. Upward $(\mathrm{Up})$ and Downward (Dw) transition periods are identified by cut lines, respectively. Winter-land vegetation dynamics (full grey line) and summer-land vegetation dynamics (cut grey line). Grey areas identify the gross benefit of the ecological winter phase (BEWP) and summer phase (BESP), respectively (Equation (2)). References: Benefit of Transhumant Annual Cycle (BTAC, Equation (3)), Effective Benefit of the Ecological Summer Phase (BESPe). 


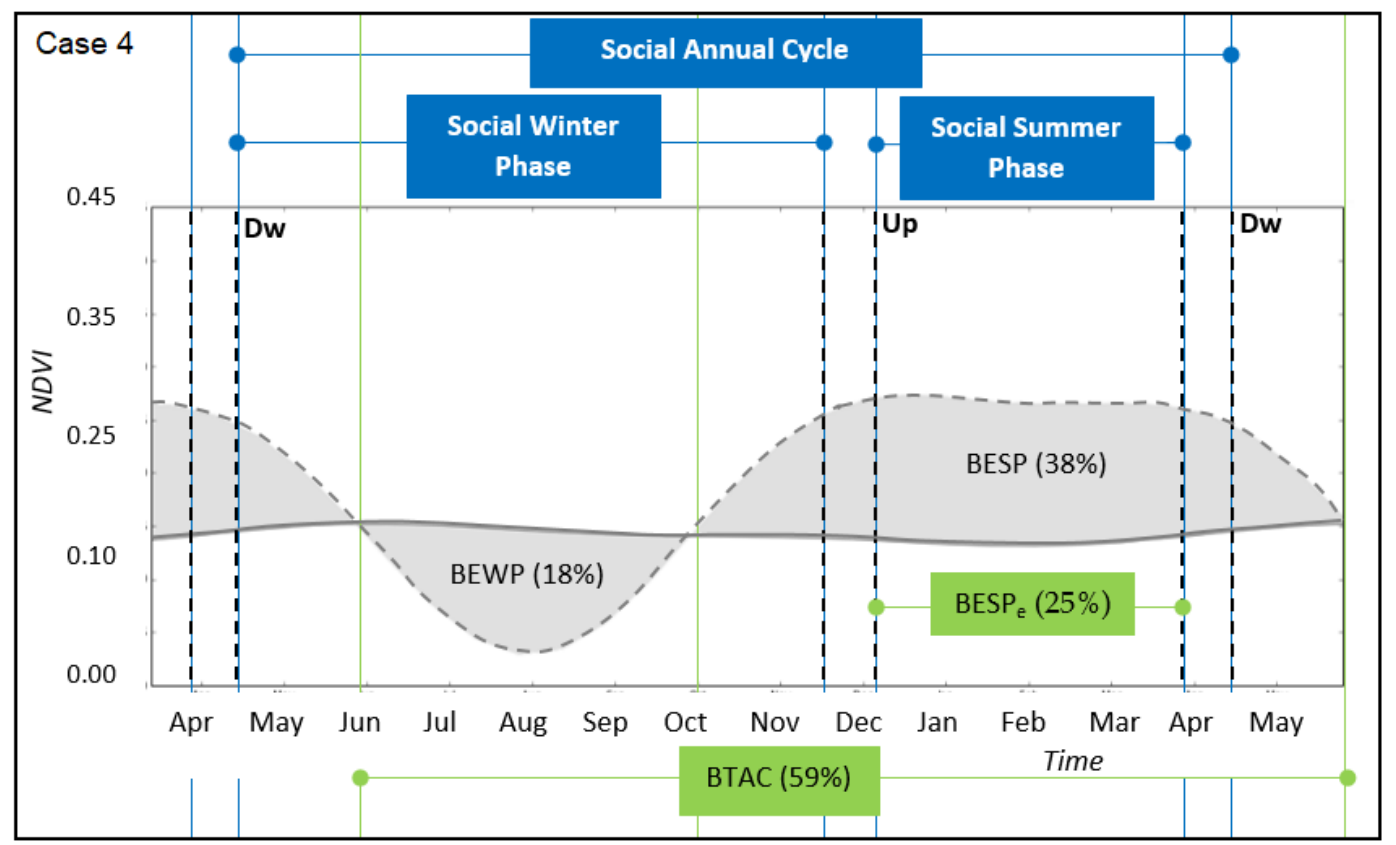

Figure 6. Transhumant annual cycle for the case study 4. Winter-phase and summer-phase along time for the social (straight blue lines) and ecological (straight green lines) system domain. Upward $(\mathrm{Up})$ and Downward $(\mathrm{Dw})$ transition periods are identified by cut lines, respectively. Winter-land vegetation dynamics (full grey line) and summer-land vegetation dynamics (cut grey line). Grey areas identify the gross benefit of the ecological winter phase (BEWP) and summer phase (BESP), respectively (Equation (2)). References: Benefit of Transhumant Annual Cycle (BTAC, Equation (3)), Effective Benefit of the Ecological Summer Phase (BESPe).

In relation to synchrony between ecological and social phases, the case with closer distances between pasturelands (case 2, Figure 4) was almost synchronised with respect to cases where distances were longer (cases 3 and 4, Figures 5 and 6, respectively). This was due to: (i) late and early starting moments of upward and downward transitions with respect to the starting and finishing moments of ecological phases, respectively, and (ii) the higher time spent during transitions for moving between sites. This asynchrony was recorded by a higher time spent in winter-lands, compared to a shorter time spent in summer-lands, which implied a less effective benefit obtained from the summer-phase and potentially an over-dependency on the winter-phase. However, there was an observed synchrony between the social summer-phase (i.e., the effective time spent in the summer-land, SSP) and the duration of the maximum productivity levels of the ecological summer-phase. In particular, the match occurred between arrival and leaving moments of pastoralists at summer-lands, and starting and finishing moments of the maximum levels of vegetation productivity, respectively (cases 3 and 4, Figures 5 and 6).

\section{Discussion}

A framework for the assessment of social and ecological phases of the transhumant annual cycle was proposed and preliminarily tested in four case studies from north-west Patagonia, Argentina. The framework provided new insights and was sensitive to capturing differences in both the social and ecological phases, as well as the relative synchrony among them, across cases. For instance, positive annual benefits for transhumant pastoralists derived from moving between winter- and summer-lands were recorded in most case studies. The relative ecological benefit provided by the summer-phase was similar to or greater than the relative ecological benefit provided by the winter-phase. The level of synchrony between social and ecological phases varied among cases, with an observed tendency for more synchronisation in the cases with closer distances between pasturelands, and asynchrony in the cases with longer distances and larger movement transitions. 
Landscape rotational pastoral use was evidenced, but with differences among cases. In the study cases with closer distances between winter- and summer-lands, corresponding to horizontal transhumance (cases 1 and 2, Figures 3 and 4, respectively), the winter and summer social phases were almost equally distributed in the social annual cycle. In the study cases with more distant pasturelands, corresponding to vertical transhumance (cases 3 and 4, Figures 5 and 6, respectively), the social winter phase was longer than the social summer phase. Hence, in the cases for which the pasturelands had a longer distance between them, there was an inverse proportion of time between the period of ecological phases and social phases, which suggests a longer grazing time spent over winter-lands than over summer-lands. A recent study on perceptions of pastoralists with such long distances between pasturelands highlighted that winter-lands were perceived as more degraded than summer-lands [27]. The relationship between a longer time spent for grazing and a concomitant degradation status needs further research. However, the results of this article provide new insights into this topic, suggesting two main explanations for this situation. First, pastoralists started the upward and downward transitions later and earlier than the starting and finishing moments of ecological phases, respectively. One major reason is that pastoralists reduce risks associated with facing climatic problems in terms of storms and snowfalls, which occur both early in the spring and in autumn in the mountains [27]. Second, the longer time spent during transitions for moving between sites was associated with longer distances and larger height differences (Table 1). Hence, the advantage of foraging in more contrasting pasturelands, as measured by higher ecological annual benefits, was not fully seized due to the time needed for transitions (Table 2). However, the social summer-phase matched the maximum productivity levels of the ecological summer-phase, suggesting that synchrony of social and ecological phases may be occurring in a shorter window of time during the summer, which we named effective benefit (BESPe, Figures 5 and 6). On the other hand, longer transition times may be associated with higher costs to reach the benefit. For example, this cost refers to the livestock energy consumption necessary to perform the transition movements, which may be positively related to distance and slope. Recent studies in analogous regions tracked the migratory routes and movements connecting pasturelands [31,32], which may be used as a complementary method to estimate movement costs. Then, a net outcome can be obtained as a difference between benefits and costs, which needs further research.

Social-ecological systems are complex and interdependent [44]. Assessing the spatial and temporal variation of ecosystem primary productivity, linked to the socio-productive responses of the transhumant activity, is of high value when understanding its interdependence [6]. The impact of the level of synchrony between ecological and social phases of transhumant pastoralism provides new insights for conservation and livestock management policies in these regions. For example, yearly modifications to ecological phases, such as a shortening of the winter-phase due to drought in winter-lands or a delay at the beginning of the summer-phase due to colder conditions in mountainous areas, may be key to informing changes in the upward or downward transitions, which may start earlier or later depending on these situations. However, modifications in the ecological phases may have a correlation with changes in the social phases and, hence in the relative grazing dependence over rangelands, as measured by larger time spent to settle in a given pastureland. The short periods determined by transitions, when pastoralists and herds move between winter- and summer-lands, are sensitive moments that influence the level of synchrony between social and ecological phases. Future research is needed to study the impact of climate change on altering the ecological cyclic dynamics, such as modifying the length and benefit of the ecological summer-phase, and the concomitant adaptive response of pastoralists to such changing conditions.

This framework can be scaled-up at a regional level as a monitoring tool aimed at informing decision-makers about changes in social and ecological phases of the transhumance activity. The main premise for a monitoring system would be that wellbeing of pastoral families strongly depend on the synchrony between these interdependent phases. Hence, an increased asynchrony between social and ecological phases would be a sensitive indicator about decoupling between provision of ecosystem services (e.g., forage for animals) and human needs. In this respect, a key future step 
should be the inclusion of temporal variability on both ecological phases (e.g., inter-annual cycles) and changes in pastoralists' movement decisions. In particular, a key issue is considering the inter-annual and seasonal changes in the level of synchrony between social and ecological phases, which may occur due to different factors. For example, climate change may speed-up snow melting in highlands, with a consequent shorter availability of water and forage productivity that may reduce the benefit of the summer-phase. On the other hand, modifications in the time spent for transitions (e.g., reducing transitions time with the use of trucks for herd movement [32]), may increase the proportion of yearly time spent in summer-lands and a concomitant reduction in time spent in the winter-lands. This situation may increase risks to summer-land factors, which need future research. Whereas we acknowledge that the proposed framework does not consider this temporal variability in this early version, we highlight that it is sufficiently flexible to be used as a starting step to move forward in developing a tool aimed at identifying changes in social and environmental dimensions of mobile systems. These applications can be of interest for currently available public policy, such as Law 3016 in Neuquén Province, Argentina, which regulates key features such as migratory roads, recognising transhumance as an environmental and cultural heritage [45]. Besides, this tool may be of interest for other mobile systems worldwide, with major opportunities for vertical transhumance, for instance under the recently recognised United Nations Educational, Scientific and Cultural Organization's (UNESCO) Intangible Cultural Heritage category [46]. This new international status demands precise structural and functional information of transhumant activity at national and regional scales, for which the approach on the synchrony of social and ecological phases may be of value for baseline layouts and as a monitoring tool of future changes. In particular, vertical transhumance involving mountainous regions such as Mediterranean zones [28] and The Alps [47], The Hymalayas [22,33], Mountains of West Africa [29,31], or central Asia [35].

The social and ecological phases of different pastoralists are highly variable regarding the environmental and productive features of their farming system. We proposed that focusing on the synchrony between phases is a synthesis of a functional feature of this empirical phenomenon, the observed pattern of which is a resultant of a socio-environmental coevolution process [9]. The particularities of different regions should be accurately defined to adapt this framework to varying circumstances. For example, we acknowledge that this framework is based on environments with contrasting winter and summer seasons, which occur in regions located in high latitudes, as in the case of Patagonia, Argentina. As regions located in low latitudes may consider dry and wet seasons [48], instead of a photoperiodic driver, as contrasting situations that promote mobility, there are many other features to take into account [49]. On the one hand, access to ecological services such as water and forage, which are offered by winter- and summer-lands at different moments of the year (or dry and wet seasons in the tropics and subtropics), depends on many different social and environmental factors. From a social perspective, land historical usage by families and local social agreements with respect to management, land access as determined by land tenure and regional infrastructure are key structural features [30]. Moreover, availability, length and conditions of herding roads define, for each pastoral household, the access to pasturelands and the type of connectivity between them [17]. From an environmental perspective, a major factor is the kind of ecosystem services supplied by each pastureland, for each transhumant system (e.g., shrub steppe, grass-shrub steppe, wetland or forest), their conservation condition and historical management [50]. In addition, the cyclic environmental dynamics, in the case of arid and semi-arid rangelands highly driven by climate [1], and their interaction with management are key features influencing the long-term ecosystem supply of water and forage productivity. In the proposed framework, a combination of these factors drives the relative level of synchrony between phases. Therefore, this heterogeneity needs future research and should be taken into consideration for a scaling-up of this framework in different regions. 


\section{Conclusions}

We proposed a framework, rooted in a coevolutionary approach, to assess the level of synchrony of social and ecological phases in transhumant pastoralism, which is a key feature of this kind of mobile social-ecological system. The framework was sensitive to capturing differences across study cases, which included vertical and horizontal transhumance, providing new insights regarding the socio-ecological interdependence in transhumant systems. The main contributions are related to measures aimed at quantifying (i) the total and relative benefit of ecological phases, in terms of the seasonal difference between rangeland productivity of winter- and summer-land, and (ii) the social phases derived from mobility, in terms of the time spent by pastoralists in each pastureland and transitions between them. The combination of these measurements provides an innovative perspective regarding the level of synchrony between these ecological and social phases, which can be a helpful approach in addressing similar issues in other regions worldwide. Besides, results are encouraging with respect to the future development of an assessment and monitoring system for regions dominated by transhumant pastoralism, aimed at informing decision makers about ecosystem conservation issues, sustainable management options and social-oriented aids.

Author Contributions: Conceptualization, M.H.E. and O.B.; methodology, O.B. and N.P.L.; software, O.B. and N.P.L.; validation, N.P.L., O.B., and M.H.E.; formal analysis, O.B., N.P.L.; investigation, N.P.L. and M.H.E.; resources, M.H.E. and O.B.; data curation, N.P.L., O.B. and M.H.E.; writing-original draft preparation, N.P.L. and M.H.E.; writing-review and editing, M.H.E. and O.B.; visualization, N.P.L. and M.H.E.; supervision, N.P.L., O.B. and M.H.E.; project administration, M.H.E.; funding acquisition, M.H.E. All authors have read and agreed to the published version of the manuscript.

Funding: This research was funded by Instituto Nacional de Tecnología Agropecuaria (INTA), grant number PRET-1281103, Ministerio de Ciencia, Tecnología e Innovación, Argentina, grant number PICT 2015-929 and under the INTA-APN (Administración de Parques Nacionales, P.N. Laguna Blanca) collaboration agreement.

Acknowledgments: Special thanks to rural families who kindly agreed to collaborate with this study during the interviews. We acknowledge the support of J.P.M., A.M., S.V. and D.C. for data gathering and two anonymous reviewers for valuable suggestions.

Conflicts of Interest: The authors declare no conflict of interest.

\section{References}

1. Reynolds, J.F.; Smith, D.M.S.; Lambin, E.F.; Turner, B.L.; Mortimore, M.; Batterbury, S.P.; Downing, T.E.; Dowlatabadi, H.; Fernández, R.J.; Herrick, J.E.; et al. Global desertification: Building a science for dryland development. Science 2007, 316, 847-851. [CrossRef] [PubMed]

2. Folke, C. Resilience: The emergence of a perspective for social-ecological systems analyses. Glob. Environ. Chang. 2006, 16, 253-267. [CrossRef]

3. Rissman, A.R.; Gillon, S. Where are ecology and biodiversity in social-ecological systems research? A review of research methods and applied recommendations. Conserv. Lett. 2017, 10, 86-93. [CrossRef]

4. Herrero-Jáuregui, C.; Arnaiz-Schmitz, C.; Reyes, M.; Telesnicki, M.; Agramonte, I.; Easdale, M.; Schmitz, M.; Aguiar, M.; Gómez-Sal, A.; Montes, C. What do we talk about when we talk about Social-Ecological Systems? A Literature Review. Sustainability 2018, 10, 2950. [CrossRef]

5. Glaser, M.; Krause, G.; Ratter, B.; Welp, M. Human/Nature interaction in the anthropocene potential of social-ecological systems analysis. Gaia-Ecol. Perspect. Sci. Soc. 2008, 17, 77-80. [CrossRef]

6. Janssen, M.A.; Anderies, J.M.; Ostrom, E. Robustness of social-ecological systems to spatial and temporal variability. Soc. Nat. Resour. 2007, 20,307-322. [CrossRef]

7. Easdale, M.H.; Domptail, S.E. Fate can be changed! Arid rangelands in a globalizing world-A complementary co-evolutionary perspective on the current 'desert syndrome'. J. Arid Environ. 2014, 100, 52-62. [CrossRef]

8. Norgaard, R.B. Sociosystem and ecosystem coevolution in the Amazon. J. Environ. Econ. Manag. 1981, 8, 238-254. [CrossRef]

9. Kallis, G. When is it coevolution? Ecol. Econ. 2007, 62, 1-6. [CrossRef]

10. Norgaard, R.B.; Kallis, G. Coevolutionary contradictions: Prospects for a research programme on social and environmental change. Geogr. Ann. Ser. B Hum. Geogr. 2011, 93, 289-300. [CrossRef] 
11. Dyson-Hudson, R.; Dyson-Hudson, N. Nomadic pastoralism. Ann. Rev. Anthropol. 1980, 9, 15-61. [CrossRef]

12. Bendini, M.; Nogués, C.; Pescio, C. Medio ambiente y sujetos sociales: El caso de los cabreros trashumantes. Debate Agrario 1993, 17, 123-130.

13. Fryxell, J.M.; Sinclair, A.R.E. Seasonal migration by white-earned kob in relation to resources. African J. Ecol. 1988, 26, 17-31. [CrossRef]

14. McNaughton, S.J.; Oesterheld, M.; Frank, D.A.; Williams, K.J. Ecosystem-level patterns of primary productivity and herbivory in terrestrial habitats. Nature 1989, 341, 142-144. [CrossRef] [PubMed]

15. Paruelo, J.M.; Epstein, H.E.; Lauenroth, W.K.; Burke, I.C. ANPP estimates from NDVI for the Central Grassland Region of the United States. Ecology 1997, 78, 953-958. [CrossRef]

16. Ruimy, A.; Saugier, B.; Dedieu, G. Methodology for the estimation of terrestrial net primary production from remotely sensed data. J. Geophys. Res. 1994, 99, 5263-5283. [CrossRef]

17. Easdale, M.H.; Aguiar, M.R.; Paz, R. The urbanization process in a transhumant pastoral territory in North-West Patagonia, Argentina (1920-2010). Cuad. Geogr. 2018, 57, $283-303$.

18. Easdale, M.H.; Aguiar, M.R.; Paz, R. A social-ecological network analysis of Argentinean Andes transhumant pastoralism. Reg. Environ. Change 2016, 16, 2243-2252. [CrossRef]

19. Arnold, E.R.; Greenfield, H.J. The Origins of Transhumant Pastoralism in Temperate Southeastern Europe; Space and Spatial Analysis in Archaeology; British Archaeological Reports Publishing: Oxford, UK, 2006; pp. $243-252$.

20. Barberena, R.; Duran, V.A.; Novellino, P.; Winocur, D.; Benítez, A.; Tessone, A.; Quiroga, M.N.; Marsh, E.J.; Gasco, A.; Cortegoso, V.; et al. Scale of human mobility in the southern Andes (Argentina and Chile): A new framework based on strontium isotopes. Am. J. Phys. Anthropol. 2017, 164, 305-320. [CrossRef]

21. Nautiyal, S.; Rao, K.S.; Maikhuri, R.K.; Saxena, K.G. Transhumant pastoralism in the Nada Devi Biosphere Reserve, India. Mt. Res. Dev. 2003, 23, 255-262. [CrossRef]

22. Moktan, M.R.; Norbu, L.; Nirola, H.; Dukpa, K.; Rai, T.B.; Dorji, R. Ecological and social aspects of transhumant herding in Bhutan. Mt. Res. Dev. 2008, 28, 41-48. [CrossRef]

23. Lanari, M.R.; Pérez Centeno, M.J.; Domingo, E. The Neuquén criollo goat and its production system in Patagonia, Argentina. In People and Animals Traditional Livestock Keepers: Guardians of Domestic Animal Diversity; Tempelman, K., Cardellino, R.A., Eds.; FAO: Rome, Italy, 2007; pp. 7-15.

24. Fernandez-Gimenez, M.E. The role of Mongolian nomadic pastoralists' ecological knowledge in rangeland management. Ecol. Appl. 2000, 10, 1318-1326. [CrossRef]

25. Ladio, A.H.; Lozada, M. Human ecology, ethnobotany and traditional practices in rural populations inhabiting the Monte region: Resilience and ecological knowledge. J. Arid Environ. 2009, 73, 222-227. [CrossRef]

26. Oteros-Rozas, E.; Ontillera-Sánchez, R.; Sanosa, P.; Gómez-Baggethun, E.; Reyes-García, V.; González, J.A. Traditional ecological knowledge among transhumant pastoralists in Mediterranean Spain. Ecol. Soc. 2013, 18, 33. [CrossRef]

27. Easdale, M.H.; Aguiar, M.R. From traditional knowledge to novel adaptations of transhumant pastoralists in the face of new challenges in North Patagonia. J. Rural Stud. 2018, 63, 65-73. [CrossRef]

28. Oteros-Rozas, E.; Martín-López, B.; González, J.A.; Plieninger, T.; López, C.A.; Montes, C. Socio-cultural valuation of ecosystem services in a transhumance social-ecological network. Reg. Environ. Change 2014, 14, 1269-1289. [CrossRef]

29. Brottem, L.; Turner, M.D.; Butt, B.; Singh, A. Biophysical variability and pastoral rights to resources: West African transhumance revisited. Hum. Ecol. 2014, 42, 351-365. [CrossRef]

30. Fernandez-Gimenez, M.E. Spatial and social boundaries and the paradox of pastoral land tenure: A case study from post-socialist Mongolia. Hum. Ecol. 2002, 30, 49-78. [CrossRef]

31. Motta, P.; Porphyre, T.; Hamman, S.M.; Morgan, K.L.; Ngwa, V.N.; Tanya, V.N.; Raizman, E.; Handel, I.G.; Bronsvoort, B.M. Cattle transhumance and agropastoral nomadic herding practices in Central Cameroon. BMC Vet. Res. 2018, 14, 214. [CrossRef]

32. Apolloni, A.; Nicolas, G.; Coste, C.; Mamy, A.B.E.; Yahya, B.; Arbi, A.S.E.; Gueya, M.B.; Baba, D.; Gilbert, M.; Lancelot, R. Towards the description of livestock mobility in Sahelian Africa: Some results from a survey in Mauritania. PLoS ONE 2018, 13, e0191565. [CrossRef]

33. Hashmi, M.M.; Frate, L.; Nizami, S.M.; Carranza, M.L. Assessing transhumance corridors on high mountain environments by least cost path analysis: The case of yak herds in Gilgit-Baltistan, Pakistan. Environ. Monit. Assess. 2017, 189, 488. [CrossRef] 
34. Sakamoto, T. Mobility and Sustainability: A Computational Model of African Pastorals. J. Manag. Sustain. 2016, 6, 59. [CrossRef]

35. Suttie, J.M.; Reynolds, S.G. (Eds.) Transhumant Grazing Systems in Temperate Asia; Plant Production and Protection Series 31; Food \& Agriculture Organization (FAO): Rome, Italy, 2003.

36. Fernandez-Gimenez, M.E.; Le Febre, S. Mobility in pastoral systems: Dynamic flux or downward trend? Int. J. Sustain. Dev. World Ecol. 2006, 13, 341-362. [CrossRef]

37. Thevenin, M. Kurdish transhumance: Pastoral practices in south-east Turkey. Pastor. Res. Policy Pract. 2011, 1, 23. [CrossRef]

38. Krätli, S.; Huelsebusch, C.; Brooks, S.; Kaufmann, B. Pastoralism: A critical asset for food security under global climate change. Anim. Front. 2013, 3, 42-50. [CrossRef]

39. Easdale, M.H.; Pérez León, N.; Aguiar, M.R. Strains in sustainability debates: Traditional Ecological Knowledge and Western Science through the lens of extension agents in a pastoral region. Rural Soc. 2020, 85, 57-84. [CrossRef]

40. Frank, M.; Easdale, M.H.; Kaufmann, B. Assessing a demonstration farm approach for technological innovations in pastoral livestock production systems of Northern Patagonia: Participants' perceptions of stakeholder roles and innovations. Exp. Agric. 2018, 54, 774-793. [CrossRef]

41. Fariña, C.; Easdale, M.H.; Bruzzone, O.; Umaña, F. Parque Nacional Laguna Blanca: Evaluación Forrajera y Dinámica de la Productividad de los Pastizales; Comunicación Técnica RRNN 35; INTA: Bariloche, Argentina, 2019; p. 41. Available online: http://hdl.handle.net/20.500.12123/5512 (accessed on 6 April 2020).

42. Hunter, J.D. Matplotlib: A 2D graphics environment. Comput. Sci. Eng. 2007, 9, 90-95. [CrossRef]

43. Rouse, J.W.; Haas, R.H.; Schell, J.A.; Deering, D.W. Monitoring vegetation systems in the great plains with ERTS. In Proceedings of the 3rd Earth Resources Technology Satellite-1 Symposium, Washington, DC, USA, 10-14 December 1973; pp. 309-317.

44. Anderies, J.; Janssen, M.; Ostrom, E. A framework to analyze the robustness of social-ecological systems from an institutional perspective. Ecol. Soc. 2004, 9, 1. [CrossRef]

45. Law 3016, Neuquén Province, Argentina. 2016. Available online: http://200.70.33.130/images2/Biblioteca/ 3016.pdf (accessed on 6 April 2020).

46. Transhumance, the Seasonal Droving of Livestock along Migratory Routes in the Mediterranean and in the Alps. 2019. Available online: https://ich.unesco.org/en/RL/transhumance-the-seasonal-droving-oflivestock-along-migratory-routes-in-the-mediterranean-and-in-the-alps-01470 (accessed on 6 April 2020).

47. Zendri, F.; Ramanzin, M.; Bittante, G.; Sturaro, E. Transhumance of dairy cows to highland summer pastures interacts with breed to influence body condition, milk yield and quality. Ital. J. Anim. Sci. 2016, 15, 481-491. [CrossRef]

48. Butt, B.; Shortridge, A.; Winkler Prins, A.M. Pastoral herd management, drought coping strategies, and cattle mobility in southern Kenya. Ann. Assoc. Am. Geogr. 2009, 99, 309-334. [CrossRef]

49. Turner, M.D.; Schlecht, E. Livestock mobility in sub-Saharan Africa: A critical review. Pastoralism 2019, 9, 13. [CrossRef]

50. Reed, M.S.; Stringer, L.C.; Dougill, A.J.; Perkins, J.S.; Atlhopheng, J.R.; Mulale, K.; Favretto, N. Reorienting land degradation towards sustainable land management: Linking sustainable livelihoods with ecosystem services in rangeland systems. J. Environ. Manag. 2015, 151, 472-485. [CrossRef] [PubMed]

(C) 2020 by the authors. Licensee MDPI, Basel, Switzerland. This article is an open access article distributed under the terms and conditions of the Creative Commons Attribution (CC BY) license (http://creativecommons.org/licenses/by/4.0/). 